\title{
Marx e a estética
}

Marx and the aesthetics

Ronaldo Rosas Reis

Ronaldo Reis é Professor

Titular aposentado da

Faculdade de Educação da

Universidade Federal

Fluminense. Credenciado permanente no Programa de

Pós-Graduação em Educação da UFF.

ronaldorosas@id.uff.br.

(D) https://orcid.org/0000-0002-4837-2650

Recebido em: 27/11/2018

Aceito para publicação em: 29/11/2018 


\section{Resumo}

$\mathrm{O}$ artigo comenta as ideias de Marx expostas no Caderno III dos Manuscritos de 1844 , destacando o papel da sensibilidade na formação estético-cultural do ser social. Analisa criticamente a dualidade estrutural dessa formação sob o regime da propriedade privada, na qual a riqueza da arte é destinada aos ricos e aos demais privações. Ao fim e ao cabo, parafraseando Lukács, o objetivo do artigo é apreender e debater as tensões dialéticas no "campo da luta entre experiências passadas e novas impressões provocadas pela arte".

Palavras-chave: Marx. Estética. Sensibilidade. Ser social. Formação estético-cultural.

\section{Abstract}

The paper comments the ideas of Marx exposing in the Book III of the Manuscripts of 1844, highlighting the role of sensibility in the aesthetic-cultural formation of the social being. It critically analyzes the structural duality of this formation under the regime of private property, in which the wonders of art is destined for the riches peoples and for other people's privations. After all, to paraphrase Lukács, the aim of the article is to apprehend and debate the dialectical tensions in the "field of struggle between experiences and new impressions provoked by art".

Keywords: Marx. Aesthetic. Sensibility. Social being. Aestheticcultural formation. 


\section{Apresentação}

Neste artigo retomo dois temas que abordei nos anos de 2004 e 2015, respectivamente'. Em ambas oportunidades se tratava de atender à exigência de ampliação do debate crítico em torno das ideias estéticas de Marx, e refletir sobre a relação arte e valor. Assim, no limite de uma exposição como essa, nosso breve percurso será o de, primeiramente, apresentar dois pensadores que precederam e influenciaram as ideias estéticas de Marx, para, em seguida, apresentar e comentar a tese marxiana acerca da sensibilidade e do seu caráter formador do ser social. Observaremos, nesse sentido, a dimensão extraordinária da dualidade nesta formação sob o regime da propriedade privada e da exploração dos sentidos do trabalhador. Em complemento, com base na orientação ontológica de Marx e com a intenção de apresentar um tema pouco estudado nos debates sobre estética e arte, mesmo nos meios marxianos, comentaremos a relação arte e valor. Ao fim e ao cabo, nosso objetivo é apreender e debater as tensões dialéticas, como diz Lukács, no "terreno da luta entre experiências passadas e novas impressões provocadas pela arte" (1978, p. 293).

\section{Dois precedentes}

Minha consciência é minha relação com o que me cerca. (Marx-Engels, 2002)

\section{Alexander Baumgarten: por uma gnosiologia da sensação}

Ao formular, em 1750, a ideia de que os sentidos e o espírito humano formam uma totalidade indissociável, o filósofo alemão Alexander Baumgarten daria início à difícil caminhada do pensamento estético em busca de uma reconciliação com a concepção de Aristóteles sobre a arte: uma ciência "semelhante à episteme" (Bayer, 1979, p. 305). Dessa forma pioneira para a época, Baumgarten caracterizaria o pensamento estético como uma gnosiologia da sensação. Ou, por outra, uma teoria do conhecimento dos sentidos humanos (Reali; Antiseri, 1988). Até então apartados tanto pelo misticismo agostiniano como pela metafísica tomista, sensibilidade e razão seriam apreendidos por Baumgarten como elementos orgânicos de um mesmo corpo, a estética, motivo pelo qual

1 Cf. REIS, 2004 e 2015. 
esta última é apresentada pelo filósofo como uma ciência com leis próprias, ou seja, autônomas da filosofia geral. Na segunda metade do século XVIII, a despeito das ideias estéticas de Baumgarten terem influenciado um grande número de teóricos na Alemanha e na Inglaterra, se verificou que tal influência era algo restrito, porquanto apropriadas e adequadas aos propósitos do ceticismo e do empirismo dominantes na época. Nesse sentido, diferentemente do encontro da sensibilidade e da razão numa totalidade, tal como concebida por Baumgarten, a estética seria reduzida ao domínio único do sentimento, cujo escopo seria o de gerar um corpo de regras para a produção da obra de arte, e de um instrumento de análise dos seus efeitos psicológicos (Idem, 1988)².

\section{Hegel e a teleologia dos fatos estéticos}

Publicados postumamente em 1835, os volumes da Estética de Hegel se aproximariam dos pressupostos aristotélicos e baumgartiano da totalidade indissociável entre sensibilidade e razão. Para Hegel a arte é "um modo de manifestação particular do espírito humano" (1977, p. 15), reconhecendo a partir disso que a estética é "uma ciência da arte integrada a um processo dialético e metafísico" (Bayer, 1979, p. 305). Seja por apreender que a estética forma "um elo necessário no conjunto da filosofia" (1977, p. 13), seja porque concebe a filosofia uma "totalidade com um começo em todas as partes, [...] sendo este começo, em todas as partes, um resultado" (Idem, pp. 15-16), Hegel considera aquela integração obrigatória. Com efeito, ao integrar a estética ao processo dialético, portanto, ao conjunto da filosofia (a Ideia Absoluta), Hegel sugere ser a realidade apreendida pelos sentidos uma representação da Razão, "um discurso estético", um "artefato cultural" por meio do qual a Vontade Coletiva, a Moral, o Direito, a Política do burguês se expressam (Eagleton, 1993). Destituída de objetividade, a atividade humana sensorial é para Hegel um mero reflexo da Ideia Absoluta, e o mundo sensível algo a ser contemplado e descrito nos termos de uma teleologia.

Pois foi precisamente essa definição que tornou a Estética de Hegel um atrativo na Inglaterra e na França. Não sendo muito bem aceita entre os teóricos alemães, as concepções hegelianas traziam alguns dos principais elementos chave do modus operandis dos artistas, arquitetos e desenhistas industriais burgueses, face à necessidade permanente de administrar conflitos mediante metamorfoses constantes do

\footnotetext{
2 Sobre este assunto ver também LURIA, A. R. Sensacion y Percepcion. Barcelona: Fontanella, 1978.
} 
télos estético. Tais ideias correspondiam, sobretudo, à percepção que aqueles profissionais faziam da importância do progresso técnico e do surgimento de novos materiais para a experimentação e o desenvolvimento de formas estéticas autônomas em relação às normas e à linguagem artística então vigentes. Por fim, se não restam dúvidas que a Estética de Hegel representou um significativo passo em direção à compreensão científica da sensibilidade e, por extensão, do fenômeno artístico, não menos verdadeiro é que ao não levar em conta a práxis humana, tais concepções deram margem ao esquematismo teleológico das academias artísticas burguesas desde meados do século XIX.

Marx

Sensibilidade e dualidade na formação humana

Observando as contradições geradas a partir dos conflitos entre as forças produtivas e as relações sociais de produção, Marx e Engels, em A ideologia alemã (2002), apreenderam que o esteticismo exagerado da classe burguesa e o brutal ascetismo da sociedade capitalista do século XIX compunham as duas faces de uma mesma moeda. Na concepção dos autores, a realidade capitalista é hostil à plenitude do desenvolvimento da capacidade humana de criar. E embora Marx e Engels afirmem que de forma alguma isso tenha sido um impedimento à criação literária e artística, da mesma forma eles insistiriam que

[...] toda essa podridão só nos dá um resultado: [...] o conflito, pois pela divisão do trabalho, acontece efetivamente que a atividade intelectual e a atividade material o gozo e o trabalho, a produção e o consumo - acabam sendo destinados a indivíduos diferentes (Marx-Engels, 2002, p. 27).

A ignorância do papel preponderante do trabalho na vida humana e das contradições daí decorrentes são, para Marx e Engels, um dos aspectos que o levaram a criticar as concepções estéticas de Hegel. De acordo com essa crítica, o idealismo hegeliano desconsidera que o indivíduo, sob o capitalismo, cria fantasmagorias acerca da sua própria representação no mundo. Da mesma forma, ao isolá-lo no interior da Razão, ou Ideia Absoluta, o idealismo hegeliano isola-o igualmente da relação com a natureza e do trabalho de transformá-la. Para Hegel, o indivíduo é levado a apreender a si próprio como um ser auto criador, estetizado pelas suas próprias experiências estéticas. Isso 
porque, ao desconsiderar a essencialidade do trabalho na vida humana, esse indivíduo "feito por si mesmo" somente pode conceber a sociedade de maneira contemplativa e crescentemente desumanizada (Idem, 2002, pp. 36-37 e p. 99). No sentido contrário, Marx e Engels dirão que a existência de uma relação somente se justifica na medida em que ela existe para o próprio sujeito, pois, sendo a consciência um produto social

[...] o será enquanto existirem os homens. [A consciência] é, antes de mais nada, apenas a consciência do meio sensível mais próximo e de uma interdependência limitada com outras pessoas e outras coisas situadas fora do indivíduo que toma consciência [...] (Marx-Engels, 2002, p. 25).

Um ano antes de Marx e Engels darem início aos escritos de A ideologia alemã, portanto, em 1844, Marx havia publicado os Manuscritos econômico-filosóficos, (2004). Nos textos Marx reconhece o caráter histórico e social da sensibilidade confrontando a dialética materialista à estética idealista de Hegel. Em linhas gerais, Marx afirma que se "pensar e ser são [...] certamente diferentes, [no entanto] estão em unidade mútua" (Idem, 2004, p. 108), não seria outro o motivo pelo qual a apropriação da efetividade humana se dá mediante o acionamento dessa efetividade nas relações sociais. Marx dirá, complementando, que sendo o indivíduo o ser social, a consciência universal de cada indivíduo é apenas a figura teórica daquilo de que o ser social é figura viva, "ao passo que hoje em dia a consciência universal é uma abstração da vida efetiva e como tal se defronta hostilmente a ela" (Idem, 2004, pp. 107). É possível constatar que, nesse ponto, Marx, toma impulso na estética baumgartiana para fazer avançar a concepção da totalidade indissociável entre sensibilidade e razão, dedicando grande parte dele ao estabelecimento de uma historicização da sensibilidade.

O pressuposto marxiano de que o processo de humanização, compreendido como objetivo vital do homem para que este desenvolva todas as suas dimensões, se faz no e pelo trabalho, traz incluída a ideia de que o trabalho é também um movimento estético. Para Marx, assim como a razão não deve ser reduzida à esfera das ideias sob o risco de se tornar uma mera abstração lógica e/ou uma ideologia, da mesma forma a sensibilidade não deve ser tratada como um fenômeno desprovido de uma materialidade. Ao apreender o próprio elemento da expressão vital do pensamento, isto é, a linguagem, como sentido humano, Marx indica que os sentidos e o pensamento nascem e se 
enriquecem da relação específica do processo de humanização da natureza por meio do trabalho. Segundo suas palavras

O homem apropria-se do seu ser universal de uma maneira universal, portanto, como homem total. Todas as suas relações humanas com o mundo, isto é, ver, ouvir, cheirar, ter paladar, tato, pensar, olhar, sentir, querer, agir, amar, em suma, todos os órgãos da sua individualidade, que são imediatos na sua forma enquanto órgãos comuns são, na sua relação objetiva, ou seu comportamento diante do objeto, a apropriação desse objeto. A apropriação da realidade humana, a maneira como esses órgãos se comportam diante do objeto, constitui a manifestação da realidade humana (Marx, 2004, p. 108).

Aqui parece evidente que, apesar do impulso tomado a partir da gnosiologia da sensação baumgartiana, a força da ideia marxiana supera os limites daquela estética, e, ao se movimentar na materialidade histórica das relações humanas, o pensamento estético de Marx inaugura uma outra ontologia, na qual se apreende que "o comportamento [do indivíduo] para com o objeto [...] é o acionamento da efetividade humana" (Idem, 2004, p. 108). Nesse sentido, Marx concebe a formação dos cinco sentidos como "um trabalho de toda a história do mundo" (Idem, idem), a partir do que ele dirá que a verdadeira ciência é aquela que começa pela nossa sensibilidade, sendo esta nada mais do que "uma forma dupla de consciência e necessidade dos sentidos". Nas palavras dele

[...é] apenas pela riqueza objetivamente desdobrada da essência humana que a riqueza da sensibilidade humana subjetiva, que um ouvido musical, um olho para a beleza da forma, em suma as fruições humanas todas se tornam sentidos capazes, sentidos que se confirmam como forças essenciais humanas [...] (Idem, 2004, p. $110)$.

Não obstante, Marx procura evitar que tal ponto de vista não encerre uma tendência à mistificação do que seja percepção sensível, posto que isso levaria o conceito a ser utilizado como uma chave gnosiológica de acesso à arte, algo como a “coruja de Minerva”, atribuída à filosofia por Hegel. Para tanto, Marx agiria em duas frentes: de um lado, segundo Eagleton (1993, pp. 147-148), apreendendo a realidade humana como uma metáfora materializada do corpo trabalhador, no qual o sistema de produção econômica representa o elemento que rege o processo de descorporificação e espiritualização de homens e mulheres; de outro lado, vinculando o conhecimento 
artístico à exigência da práxis social, mediante a qual os sentidos humanos adquirem uma consciência teorética. Ou seja, segundo Marx, os sentidos (olhar, paladar, sonoro, olfativo, tátil) se tornam humano quando o objeto apreendido se torna social, condição, resumindo, "proveniente de homem para homem" (Marx, 2004, p. 109). O pensador alemão analisa em seguida a dualidade da sensibilidade como parte da estrutura constitutiva da práxis social. Para ele, na medida em que a propriedade privada se apresenta como a expressão sensível do estranhamento do homem em relação ao seu próprio corpo, tal condição indica que sob esse regime a plenitude sensível de homens e mulheres se reduz ao simples ato de suprir suas necessidades elementares. Decorre daí uma ruptura da vida sensível, posto que nas condições examinadas o corpo trabalhador se encontra devastado pela necessidade de sobrevivência, limitado pela monotonia, a repetição, em suma, anestesiado de seus próprios sentidos. Aprofundando o caráter geral e específico dessa ruptura, Marx considera, sob o regime da propriedade privada, um duplo problema o estranhamento do objeto e do meio criativo em decorrência do trabalho executado. Não apenas porque o produto do trabalho não pertence ao indivíduo que o realizou, mas também porque a sua criatividade é reificada sob a forma de mercadoria como força de trabalho. Ora, se a história traduz a luta do homem pelo autocontrole da sua sensibilidade, tudo o que lhe é extensivo, da sociedade à tecnologia, se impõe como uma dualidade a ser superada como forma de recuperar a humanidade pilhada pelo trabalho empregado na produção da mercadoria. Acontece que, nos termos de Marx, sob o capitalismo, a força de trabalho é uma mercadoria como todas as outras, portanto, é valor, e, como tal, determinado como decorrência da natureza mesma do fenômeno (2004a, pp. 200-203). Nessa condição, Marx dirá que o regime da propriedade privada expressa sensivelmente o estranhamento do homem sobre seu próprio corpo, projetando a vida sensível (ou realidade corpórea) em direções antitéticas.

Com efeito, numa direção se encontra o corpo ocioso do desocupado das elites que, sem qualquer necessidade de sobrevivência, aliena-se da vida sensível, percebendo-se um aleijão. Sua vantagem sobre o próprio corpo, segundo Eagleton (1993), é que o seu dinheiro "recupera vicariamente a sua sensibilidade alienada pelo poder do próprio capital", ainda que isso resulte num "corpo fantasma", um "alter ego 
zumbi a recolher satisfações de segunda mão" (Idem, p. 149)3. A outra direção para onde se dirige a vida sensível é aquela na qual se encontra o corpo trabalhador. Devastado pela necessidade de sobrevivência, o corpo trabalhador percebe-se limitado pela fronteira da monotonia, da repetição, em suma, anestesiado dos seus próprios sentidos, o trabalhador transforma seus impulsos criativos em instintos. Em outras palavras, se no nível da existência sensorial o indivíduo se encontra em condições de transcender suas próprias limitações mediante a utilização da sua criatividade, sob o regime histórico da propriedade privada e da exploração do trabalho assalariado, o indivíduo se encontra “cegamente biologizado" (Eagleton, 1993, p. 149). Nas palavras de Marx

Para o homem faminto não existe a forma humana da comida, mas somente a sua existência abstrata como alimento; poderia muito bem existir na forma mais rudimentar, e não como dizer em que esta atividade de se alimentar se distingue da atividade anima/ de alimentar-se. $(2004 \text {, p. } 110)^{4}$

Conforme dissemos mais acima, Marx não via na condição hostil da sociedade burguesa um impedimento para o trabalhador criar e fruir esteticamente, todavia ele chamaria a atenção para a dualidade na qual "os trabalhadores produzem maravilhas para os ricos - palácios, obras de arte, filosofia etc. - e para eles mesmos, trabalhadores, somente privações, casebres, deformações, imbecilidade e cretinismo" (2004, p. 82). A partir dessas considerações podemos concluir este primeiro tópico tomando como referência para o desenvolvimento seguinte a questão substantiva da dualidade estrutural da práxis social. Nele abordaremos a relação entre arte e valor considerando centralmente as tensões dialéticas nas relações sociais de produção da arte, sendo, de um lado, o trabalho do artífice, a atribuição do preço equivalente em dinheiro do objeto produzido, o meio de avaliação, circulação, exposição e comercialização do objeto artístico, e de outro lado a particularidade da receptividade do objeto artístico.

\footnotetext{
3 Para citarmos apenas um exemplo, observe-se a simetria entre o crescimento e a valorização da subjetividade e a estetização do dinheiro em meio a vertiginosa expansão do capitalismo no curso do século XX. Ao ponto de, nas condições atuais do capitalismo tardio, os desejos imaginários do parasita social e o dinheiro se constituírem num fenômeno puramente estético.

4 Grifo do autor.
} 


\section{Arte e valor}

Na sociedade burguesa, a quase totalidade dos textos com peso institucional sobre a arte, portanto, reconhecidos pela maior parte dos estudiosos, desconsidera as relações sociais presentes na sua produção, e, especialmente, a particularidade do lugar ocupado pelo ser social no conjunto dessas relações. Como diz Martins (2005, p. 123), sob o capitalismo, as obras de arte são apresentadas como objetos "já cristalizados enquanto criação artística, intrinsecamente distintos dos demais", sendo esses últimos tidos como utensílios, objetos sem valor artístico inerente e submetidos a diferentes fins circunstanciais. Quer dizer, apesar da produção artística circular por galerias, museus, centros culturais etc., de ser cotada e negociada por marchands, galeristas, colecionadores e leiloeiros, o valor artístico atribuído à obra não oferece garantia alguma de que a mesma tenha sido historicamente apropriada pelo meio social sob a forma de conhecimento sensível. Portanto, sem elementos que confiram substância de valor ao trabalho artístico que gerou a obra de arte. Parece natural que o senso comum tenha por ela, a obre de arte, o entendimento de que a arte em geral é algo desencarnado da história. Que não expressa nenhum sentido do trabalho e do conhecimento humano, e que é resultado de uma inspiração divina, mágica. Sem dúvida, se reconhecemos na concepção burguesa uma flagrante contradição entre a materialidade do sujeito social presente na obra de arte e a determinação do seu valor artístico, por certo devemos questionar o pressuposto da autonomia da arte em vista da sua circulação sob o modo de produção capitalista. A partir dessas formulações preliminares penso ser necessário associá-las à problemática do valor em geral na teoria marxiana.

Seguindo os passos de Marx na exposição do "método da economia política", na introdução dos Grundrisse (2011, pp. 54-61)5, mais especificamente na abordagem acerca da realidade da lei do valor na economia capitalista, nosso autor assinala que assim como o trabalho, o valor é uma "categoria antediluviana" (p. 55), sendo, portanto, anterior ao modo de produção capitalista. Marx segue dizendo que na medida em que

\footnotetext{
${ }^{5}$ Em um artigo ainda inédito, Mario Duayer argumenta que nos Grundrisse "Marx descreve os procedimentos da ciência em geral e não seu método, e é por isso que se pode inferir que a resolução da questão não é propriamente metodológica, epistemológica ou gnosiológica, mas ontológica" (2018, p.1). Para nós, a importância desta concepção está em seu posicionamento frente aos sistemas teóricos em disputa. Segundo Duayer, como crítica ontológica, a crítica da economia política restaura a historicidade da economia política, abre à prática humana a possibilidade de sua transformação e, em suma, "contribui para a criação de outra ontologia em que a humanidade não está condenada à reprodução infinita dela ou a ser mero espectador da história como contingência absoluta" (Idem, p. 10).
} 
A sociedade tem de estar continuamente presente como pressuposto da representação, a categoria simples do valor pode expressar [...] relações subordinadas de uma totalidade desenvolvida que já teve uma existência histórica antes que o todo se desenvolvesse no sentido que é expresso em uma categoria mais complexa (Idem, pp. 55-56).

Com efeito, Marx afirma que se na sociedade capitalista a manifestação do valor se apresenta em sua forma plenamente desenvolvida, pois somente nessa sociedade a produção de mercadorias (incluindo o trabalho) se converte na forma geral de produção, torna-se necessário partir do valor [e não do trabalho] para alcançarmos para o conceito de capital6. A partir dessas considerações gerais acerca do valor na sociedade burguesa podemos voltar ao exame do valor artístico, todavia, seguindo ainda os passos do pensador alemão nos Grundrisse.

Mais adiante, ainda na introdução, os argumentos de Marx que expõem sobre as questões da produção, distribuição, consumo e circulação na sociedade capitalista, se estendem para as formas de consciência em relação às relações de produção e de intercâmbio (2011, pp. 61-64). No sexto ponto, mencionando "a relação desigual do desenvolvimento da produção material com o desenvolvimento artístico", o pensador alemão sublinha "não conceber [em qualquer hipótese] o conceito de progresso na abstração usual" (Idem, p. 62). Um pouco mais adiante, Marx desenvolve um rico extrato no qual reflete sobre a dificuldade de compreendermos o fato da arte grega ainda nos proporcionar prazer artístico, pois, conforme suas próprias palavras, "não é possível a um homem voltar a ser criança sem se fazer infantil” (Idem, p. 63). Nesta reflexão é possível reconhecer não apenas a síntese marxiana de que "a anatomia do homem é a chave para a anatomia do macaco" (Idem, p. 58), como parece-nos muito claro a referência que ele faz aos seus próprios escritos estéticos de 1844, acerca da historicidade da sensibilidade. Portanto, temos aí recuperado dialeticamente o pressuposto ontológico da totalidade, no qual encontramos, de um lado, o ser social que caminha em direção a arte e, em sentido contrário, a eficácia estética do objeto artístico fazendo os homens reviverem os fatos reais "como algo essencial à própria vida, como momento importante também para a própria existência individual" (Lukács, 1978,

\footnotetext{
6 Segundo Rosdolsky, “a primeira determinação do capital consiste em que o valor originário da circulação [é] o movimento no qual ele se posiciona como um valor e se realiza como valor" (2001, p.147). Contribuindo com essa compreensão, Araújo diz ser "a relação social capitalista fundada na compra da força de trabalho mercantil pelas personificações da lógica do capital, tem determinação causal ontológica, a produção de bens em grande escala". (ARAÚJO, 2017, p. 2)
} 
p. 290). A partir deste conjunto de argumentos podemos inferir que o valor artístico de uma obra de arte é, nos termos lukcasianos, determinado pela sua eficácia social e humanista. Todavia, como lembra Lukács, esta eficácia "não consiste somente em uma embriaguez da receptividade direta, pois ela [a eficácia] tem um antes e um depois" (1978, p. 292). Para o filósofo húngaro sendo

[...] evidente que qualquer sujeito receptivo coloca em confronto constante a realidade refletida pela arte com as experiências por ela adquiridas, [...] se torna inteligível o fato de que quando a eficiência é produzida muitas vezes nasce uma luta entre experiências passadas e novas impressões provocadas pela arte. E o terreno dessa luta é precisamente a correspondência do todo (Idem, p. 293).

\section{Conclusão}

Ao ressaltarmos ao longo desse texto o caráter estrutural da dualidade na práxis social, isto é, como parte da estrutura mesma do modo de produção capitalista, deixamos intencionalmente de lado a questão da educação estética. Retomo Marx a fim de colocar um termo nessas ideias. Examinando no Capital (2004a, p. 20) o custo da reposição da força de trabalho extinta por morte ou desgaste do trabalhador, Marx calcula que a educação ou treinamento dos seus filhos tem um custo variável "de acordo com o nível de qualificação: se ínfimo para a força de trabalho comum, entram no total dos valores gastos para a sua produção". Já para a classe burguesa os investimentos em educação formal em geral e a educação estética em particular não tem fim.

Nas mãos do Estado burguês, seja para garantir a universalidade do belo como imagem positiva da burguesia no meio social, seja para atender aos interesses específicos do mercado de arte, a dimensão pragmática e o fim prático dos sentidos da arte são apropriados, mediados e finalmente metamorfoseados de acordo com os interesses e necessidades do momento. Desenhado como um projeto teleológicoeducativo à maneira de Schiller (1989) - e também, por extensão, de Hegel -, a estética do belo e o télos artístico burguês são sobrepostos a qualquer outra demanda social. Não sendo por outro motivo que mais acima chamamos a atenção para o fato de que sob o capitalismo a arte é apreendida pelo senso comum como algo estranhado. A velocidade da circulação de mercadorias no curso do século XX até a nossa época, não somente fez aumentar esse estranhamento como transformou os desejos imaginários da burguesia e o dinheiro em um fenômeno puramente estético. Fazendo referência à negatividade 
produzida pela indústria do entretenimento, o historiador Eric Hobsbawm sublinhou ironicamente que constitui um fato extraordinário que ela não tenha logrado "fazer do público um bando de idiotas" (1991, p. 37).

No atual estado de desenvolvimento capitalista, momento qualificado por Lukács como de uma "solidão ontológica peculiar" (1969, p. 38), e no qual é razoável admitir que retomando Mario Duayer $(2018$, p. 1) - "as interpretações mais influentes [do marxismo] não conseguem dar conta da orientação ontológica do texto marxiano", me preocupa o fato de que no caso particular do tema aqui examinado não tenhamos conseguido refletir com a profundidade exigida sobre a sensibilidade e a arte no tempo presente. De todo modo, reconhecendo a necessidade e a urgência de mantermos viva a ideia de Lukács acerca da luta da arte pela emancipação humana, penso na importância da esquerda na América Latina manter um foro permanente de debates marxistas sobre a estética e a arte.

\section{Referências}

ARAÚJO, Paulo Henrique Furtado. "Notas críticas à compreensão de Lênin sobre o Estado: revisitando O Estado e a Revolução". In: ANAIS DO XII CONGRESSO BRASILEIRO DE HISTÓRIA ECONÔMICA. Niterói, 2017. Disponível em:

<http:/ / www.abphe.org.br/uploads / ABPHE\%202017/30\%20Notas\%20Cr\%C3\%ADticas\%20 \%C3\%A0\%20compreens\%C3\%A3o\%20de\%20L\%C3\%AAnin\%20sobre\%200\%20Estado\%20revis itando\%200\%20Estado\%20e\%20a\%20Revolu\%C3\%A7\%C3\%A3o.pdf>. Acesso em: 29 nov. 2018.

BAYER, Raymond. História da estética. Lisboa: Estampa, 1979.

DUAYER, Mario. Marx: O Método da Economia Política como Crítica Ontológica. Niterói, RJ: original cedido pelo autor, 2018.

EAGLETON, Terry. A ideologia da estética. Rio de Janeiro: Jorge Zahar Editor, 1993.

HEGEL, G. W. F. Lecciones de estética. Buenos Aires: La Pléyade, 1977.

HOBSBAWM, Eric J. História social do jazz. São Paulo: Paz e Terra, 1991. 
LURIA, A.R. Sensación y Percepción. Barcelona: Fontanella, 1978.

LUKÁCS, György. Introdução à estética marxista. Rio de Janeiro: Civilização Brasileira, 1978. Tradução: Leandro Konder.

MARTINS, Luiz Renato. "A arte entre o trabalho e o valor". In Crítica Marxista n 20. Campinas, SP: UNICAMP/CEMARX, 2005.

MARX, Karl; ENGELS, Friedrich. A ideologia alemã. São Paulo: Martins Fontes, 2002. Tradução: Luís Claudio Costa.

MARX, KARL. Manuscritos econômico-filosóficos. São Paulo: Boitempo, 2004. Tradução: Jesus Ranieri.

. Grundrisse. São Paulo: Boitempo, 2011 . Tradução: Mario Duayer e Nélio Schneider.

. O capital. Vol. 1 Rio de Janeiro: Civilização Brasileira, 2004a. Tradução: Reginaldo S'Antanna.

REALI, G.; ANTISERI, D. História del pensamiento filosófico y científico. Barcelona: Herder, 1988, p. 694-695.

REIS, Ronaldo Rosas. "Trabalho e conhecimento estético". In Trabalho, educação e saúde. Rio de Janeiro: Escola Politécnica Joaquim Venâncio, FIOCRUZ, 2004, p. 227-250. http://www.scielo.br/pdf/tes/v2n2/02.pdf

. "Arte e cidade. Considerações críticas sobre arte e valor na sociedade de classes". In: Kriterion: Revista de Filosofia. Belo Horizonte, MG: UFMG, 2015, p. 317-333. Disponível em:

<http:/ / www.scielo.br/scielo.php?pid=S0100512X2015000200317\&script=sci_abstract \&tlng=pt $>$. Acesso em: 29 nov. 2018.

ROSDOLSKY, Roman. Génesis e estrutura do Capital. Rio de Janeiro: UERJ/Contraponto, 2001.

SCHILLER, Friedrich. A educação estética do homem. São Paulo: Iluminuras, 1989.

Tradução: Roberto Schwarz; Márcio Suzuki. 